Special portable equipment was designed based on this method. The equipment makes the interpretation of radio-echo sounding data simple. It eliminates distortions of echo signals because of receiver overloading by powerful impulses, automatically records the form and intensity of signals, makes its amplitudes proportional to reflection characteristics of the ice bed and inhomogeneities of the glacier body, and makes automatic statistical analysis. The thickness of a glacier, and the position of inhomogeneities within its body, are determined given more than ten radio-echo signal positions.

The method and the equipment have been used to determine thicknesses of Lednik Dzhankuat (Caucasus). Radio-echo sounding data have been compared with data obtained by other geophysical methods and thermal drilling. There is a good agreement ( $\pm 10 \mathrm{~m}$ when the ice thickness is about $100 \mathrm{~m}$ ).

\title{
INTERPRETATION OF RADIO-EGHO SOUNDING DATA ON A TEMPERATE MOUNTAIN GLACIER FROM ITS SURFACE
}

\author{
By V. S. Luchininov \\ (Leningradskiy Ordena Lenina Elektrotekhnicheskiy Institut im. V. I. Ul'yanova (Lenina), \\ Leningrad, U.S.S.R.) \\ and Yu. Ya. Macheret \\ (Institut Geografii AN SSSR, Staromonetny 29, Moscow rogor 7, U.S.S.R.)
}

\begin{abstract}
Temperate mountain glaciers have specific peculiarities which make the interpretation of radio-echo sounding data much more difficult than for polar ice sheets. On the $\mathrm{A}$ or $\mathrm{Z}$ indicators one can observe a plurality of pulses differing in shape, amplitude, and range. Often a gap is observed on the film. The problem is to select the pulses from the bed or internal reflecting horizon and to reconstruct the subglacial relief or internal interface.

During preliminary processing, the radio-coordinates of all marks on a type A radiogram are written into a table. Then non-informative marks are eliminated and informative marks are situated on a continuous line or trace.

We put into practice three methods of interpretation: (I) an envelope method, (2) Harrison's transformation method, (3) approximation of segments of a trace by straight lines. Harrison's transformation method is the most general one; the others are useful for the presentation of results in a graphical form. The suggested methods are used for the interpretation of the data from a transverse profile of the valley glacier Lednik Bezengiy, Caucasus, 1970-7I. Radar RW-Io with a carrier frequency of $44^{\circ} \mathrm{MHz}$ and overall receiver sensitivity relative to the transmitter pulse power $130 \mathrm{~dB}$ was used. It was revealed that the transparency of the glacier changes from year to year. The maximum ice thickness measured was $330 \pm 15 \mathrm{~m}$. Some extended interfaces in the body of the glacier were discovered. One of them, $80 \mathrm{~m}$ deep, coincides with seismic contrast interface and with the $0^{\circ} \mathrm{C}$ isotherm. Radio-echo sounding data are in agreement with gravity measurements on the same profile.
\end{abstract}

